\title{
Synthesis of Isomers of Eugenol ${ }^{1}$
}

\author{
Gerhard M. Brauer, Richard Warren Morris, ${ }^{2}$ and Willard B. Howe ${ }^{2}$
}

\author{
(February 12, 1963)
}

\begin{abstract}
In connection with an investigation of the correlation between structure and reactivity of eugenol isomers, o-eugenol, 3-allyl-2-methoxyphenol and chavibetol were synthesized. A five-step synthesis was found to be most suitable for the preparation of 3-allyl-2-methoxyphenol. An improved separation of chavibetol from eugenol was achieved by gas chromatography.
\end{abstract}

\section{Introduction}

Slurries of zinc oxide and eugenol (I) harden to form a cementitious product which has found many applications in dentistry. A prior investigation of the setting mechanism showed that the hardened mass consists of zinc oxide embedded in a matrix of chelated zinc eugenolate [1]. ${ }^{3}$ It therefore appeared of interest to study the properties and reactivity of all eugenol isomers capable of forming chelates with metal oxides, i.e., o-eugenol (II), 3-allyl-2-methoxyphenol (III) chavibetol (IV) and their respective propenyl isomers.

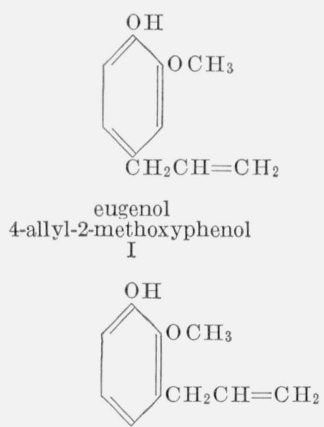

3-allyl-2-methoxyphenol III
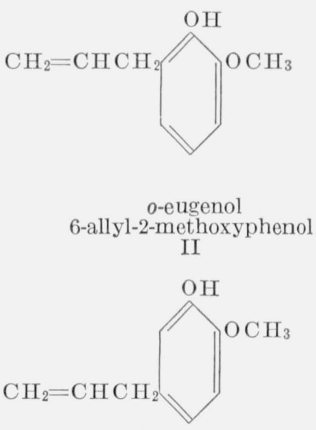

chavibetol 5-allyl-2-methoxyphenol
The present paper describes methods for synthesizing some of these compounds. In a subsequent paper the structure of the isomers will be correlated with their ultraviolet and infrared absorption spectra, ionization constants and reactivity with metal oxides.

Three procedures were considered for the synthesis of 3-allyl-2-methoxyphenol (III). (1) Partial de- methylation of 1-allyl-2,3-dimethoxybenzene (a prep-

1 The research work was supported by grants from the Office of Navy Research, Contract ONR P.J.-NR 105-210 (1-29-59), the Army Dental Corps and the Dental Sciences Division of the School of Aviation Medicine.

2 Guest worker, U.S. Army.

Figures in bracksts indicate the literature references at the end of this paper. aration analogous to that described by Hirao [2] and Schöpf and coworkers [3] for the synthesis of Chavibetol). The isomeric products II and III appeared. to be difficult to separate by techniques other than gas chromatography. (2) Claisen rearrangement of allyl 2-benzoyloxyphenyl ether followed by methylation and by subsequent hydrolysis of the benzoyl group. However, the rearrangement gave 1-allyl2,3-dihydroxybenzene instead of the desired intermediate. (3) The procedure outlined in figure 1; this synthesis proved to be successful. ${ }^{4}$

The preparation of IV was also attempted by several methods. The synthesis of pure chavibetol described by Hirao [2] and Schöpf and coworkers [3] proved to be laborious in the separation of chavibetol from its eugenol isomer. This separation has now been greatly facilitated by the use of gas chromatography.

\section{Experimental Procedures}

\section{1. o-Eugenol (6-Allylguaiacol) ${ }^{5}$ (II) and o-Eugenol Benzoate}

o-Eugenol was synthesized from guaiacol in 67percent yield by the procedure of Allen and Gates [5]. The infrared spectrum is given in figure 2 . $o$-Eugenol benzoate was prepared by refluxing o-eugenol with benzoyl chloride. The solution was poured into cold water and the mixture extracted with ether. The ether solution was washed successively with dilute $\mathrm{NaOH}$ and $\mathrm{HCl}$ and evaporated. After recrystallizations from aqueous ethanol and from ether the solid melted at 59 to $60{ }^{\circ} \mathrm{C}$.

Anal: Calcd. for $\mathrm{C}_{17} \mathrm{H}_{16} \mathrm{O}_{3}: \mathrm{C}, 76.1 ; \mathrm{H}, 6.0$. Found: C, $76.6 ; \mathrm{H}, 6.0$.

\subsection{3-Allyl-2-methoxyphenol (3-Allylguaiacol) (III)}

o-Hydroxyacetanilide (2'-Hydroxyacetanilide) (V).

${ }^{4}$ Since completion of this work, the preparation of III from 0-nitrophenol [4] has come to our attention.

5 Throughout this paper the systematic names employed by Chemical Abstracts are given parenthetically at the first mention of the compound in the experimental
section. 


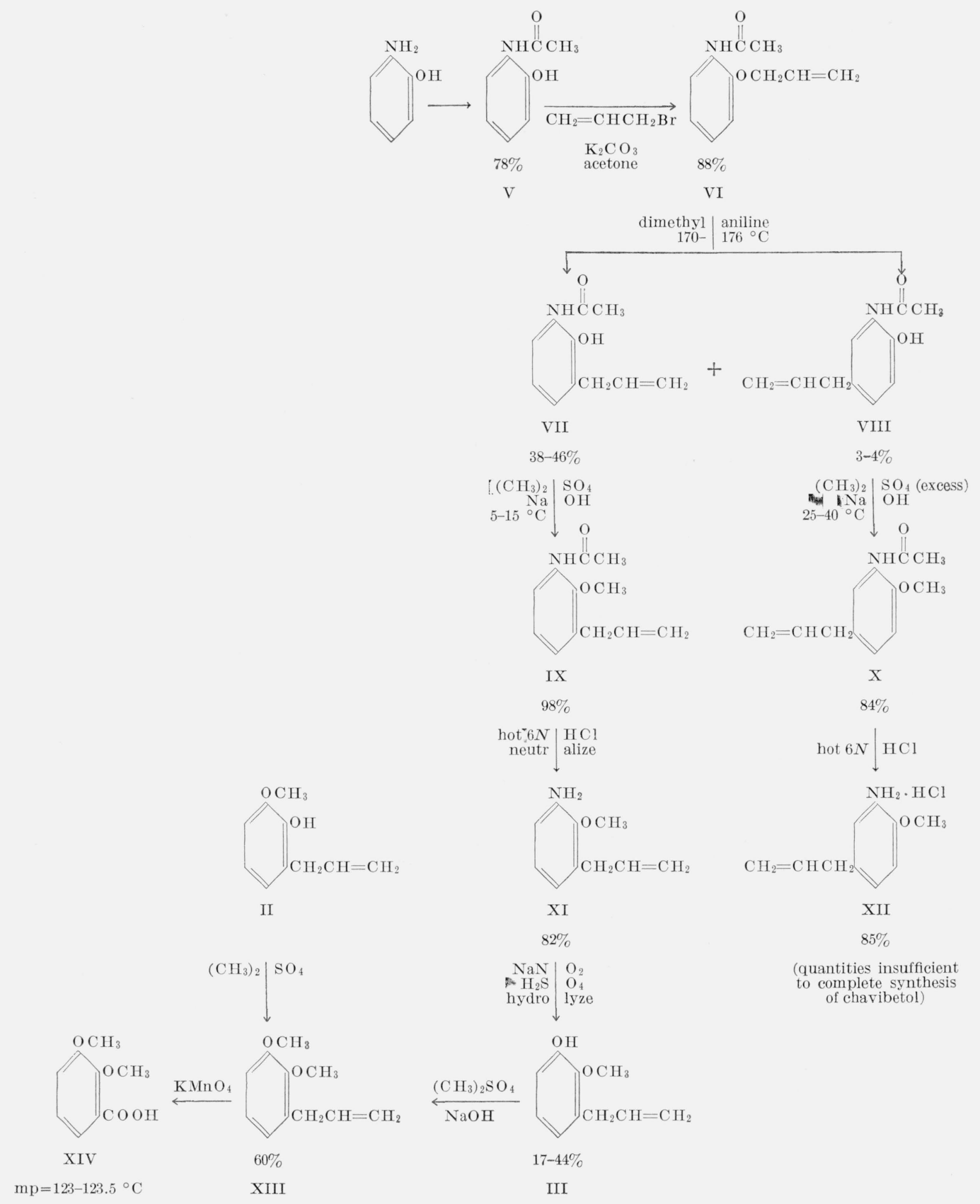

Figure 1. Synthesis of 3-allyl-2-methoxyphenol (III).

This compound was synthesized from $283 \mathrm{~g}$ (2.59 mole) of $o$-hydroxyaniline according to the procedure of Fierz-David and Kuster [6] and recrystallized from acetone. Yield: $307 \mathrm{~g}$ (78 percent).
o-Hydroxyacetanilide Allyl Ether (2'-Hydroxyacetanilide Allyl Ether) (VI). This compound was synthesized as described by Tiffany [7]. Yield: 88 percent. 


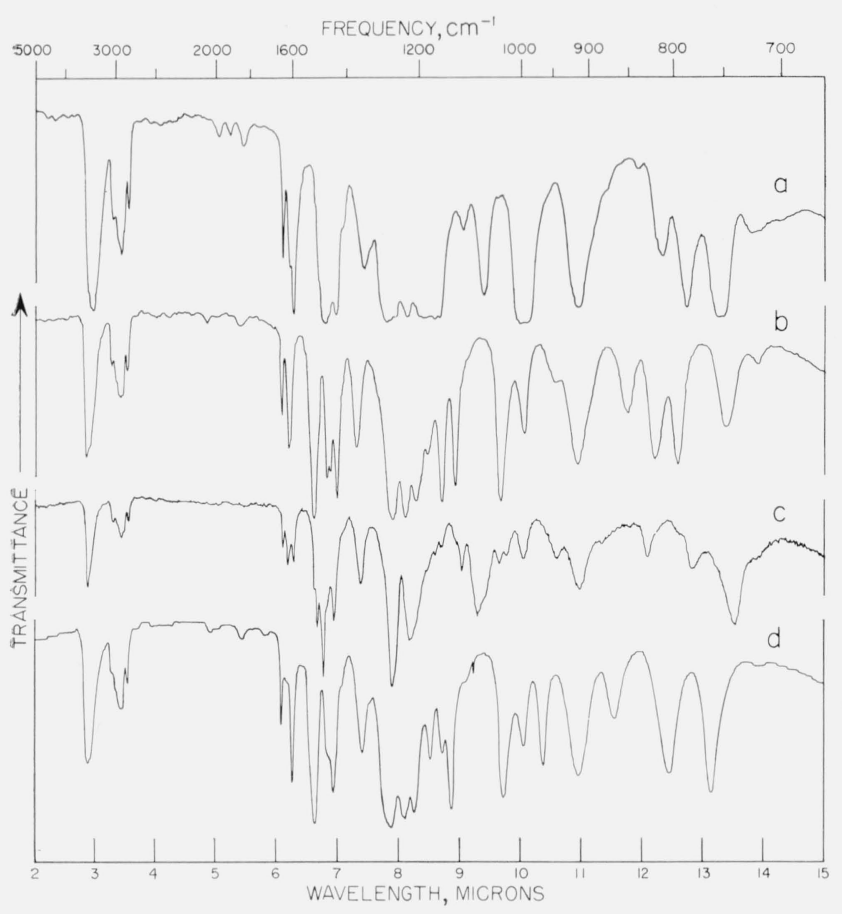

FIGURE 2. Infrared absorption curves of eugenol and its isomers.

Top to bottom: (a) 3-allyl-2 methoxyphenol, (b) eugenol, (c) o-eugenol, (d) havibetol.

3-Allyl-2-hydroxyacetanilide (3'-Allyl-2'-hydroxyacetanilide) (VII) and 5-Allyl-2-hydroxyacetanilide (5'Allyl-2'-hydroxyacetanitide) (VIII). The Claisen rearrangement of VI was conducted in dimethylaniline at 170 to $176{ }^{\circ} \mathrm{C} \quad$ [7]; time of reflux varied from $1 \frac{1}{2}$ to $4 \mathrm{hr}$. The two isomers were fractionally recrystallized and separated as described previously [7]. Faster separation was obtained by repeated fractional precipitation from $1 N \mathrm{NaOH}$ by the addition of $0.5 \mathrm{~N} \mathrm{H}_{2} \mathrm{SO}_{4}$ [8]. Yield of VII, 38 to 46 percent, mp 114 to $115^{\circ} \mathrm{C}$; vield of VIII, 3 to 4 percent, $\mathrm{mp} 115$ to $116{ }^{\circ} \mathrm{C}$. The purity of the isomers was determined by mixed melting points.

The infrared spectra of the isomers are shown in figures $3 \mathrm{a}$ and $3 \mathrm{~b}$. The spectra are useful in detecting isomerization of the allyl group to the propenyl, a change which takes place readily. Presence of the allyl group is indicated by the out-of-plane vibrations of the $=\mathrm{CH}_{2}$ and $=\mathrm{CH}$ - groups which give rise to two strong absorptions, one between 9.97 and $10.12 \mu$ and the other between 10.93 to 11.09 $\mu$ [9]. Intramolecular hydrogen bonding between the phenolic hydrogen and the carbonyl is indicated by the shift of the acetamido carbonyl absorption (usually occuring near $5.99 \mu$ ) to $6.09 \mu$.

3-Allyl-2-methoxyacetanilide (3'-Allyl-o-acetanisidide) $(I X)$. 3-Allyl-2-hydroxyacetanilide (156 g, 0.82 mole) dissolved in $500 \mathrm{ml}$ of water containing $39.2 \mathrm{~g}$ (0.98 mole) of $\mathrm{NaOH}$ was cooled to $5^{\circ} \mathrm{C}$, and nitrogen was passed over the solution. Dimethyl

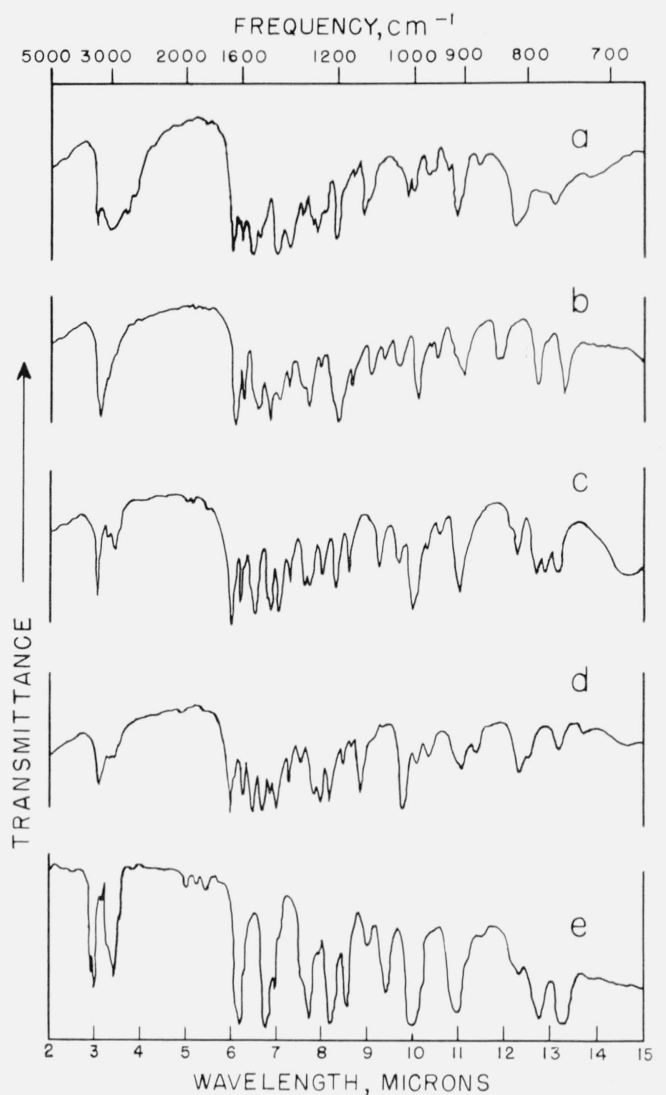

FIGURE 3. Infrared absorption curves of intermediates.

Top to bottom: (a) 3-allyl-2-hydroxyacetanilide, (b) 5-allyl-2-hydroxyacetanilide, (c) 3-allyl-2-methoxyacetanilide, (d) 5-allyl-2-methoxyacetanilide, (e) 3-allyl2-methoxyaniline. Materials (a) through (d) were in the form of potassium iodide pellets; material (e) was a liquid.

sulfate $(100 \mathrm{ml}, 1.055$ moles) was gradually added during $1 \mathrm{hr}$ to the stirred solution, which was kept at 5 to $12{ }^{\circ} \mathrm{C}$. Additional dimethyl sulfate $(30 \mathrm{ml}$, 0.32 mole) was added during a period of $2 \frac{1}{2} \mathrm{hr}$. The reaction mixture, warmed to room temperature, was made alkaline and extracted with ether. On evaporation of the extract and crystallization of the residue from ligroin or 50-percent aqueous ethanol, colorless platelets were obtained. Yield: $163 \mathrm{~g}$ (98 percent), $\mathrm{mp} 86$ to $87^{\circ} \mathrm{C}$.

Anal: Calcd. for $\mathrm{C}_{12} \mathrm{H}_{15} \mathrm{NO}_{2}: \mathrm{C}, 70.3 ; \mathrm{H}, 7.4 ; \mathrm{N}$, 6.8. Found: $\mathrm{C}, 70.4 ; \mathrm{H}, 7.2 ; \mathrm{N}, 6.9$.

The infrared spectrum is given in figure $3 \mathrm{c}$.

3-Allyl-2-methoxyaniline (3'-Allyl-o-anisidine) (XI) and its Hydrochloride. 3-Allyl-2-methoxyacetanilide (46.6 g, 0.23 mole) was refluxed for $80 \mathrm{~min}$ with $45 \mathrm{ml}$ of $6 \mathrm{~N} \mathrm{HCl}$. The solution was made alkaline with 10-percent $\mathrm{NaOH}$, and the oily layer was separated. Ether extracts of the aqueous layer were added to the brown oil. After evaporation of the ether the remaining oil was distilled at $3.5 \mathrm{~mm}$ in the presence of a little hydroquinone (to minimize polymer formation). The liquid turned brown on standing in air. Yield: $30.3 \mathrm{~g}(82 \%)$. For further purification some of the product was fractionated in a Piros-Glover spinning-band still (bp 78 to $80^{\circ} \mathrm{C}$ at less than $\left.1 \mathrm{~mm}\right) ; n_{\mathrm{D}}^{25}=1.553$. 
Anal: Calcd. for $\mathrm{C}_{10} \mathrm{H}_{13} \mathrm{NO}: \mathrm{C}, 73.6 ; \mathrm{H}, 8.0 ; \mathrm{N}$, 8.6. Found: C, $73.5 ; \mathrm{H}, 8.0 ; \mathrm{N}, 8.3$.

The absence of characteristic infrared absorption bands (fig. 3c) for cis and trans $-\mathrm{CH}=\mathrm{CH}-$ indicates that little, if any, of the propenyl isomer was present.

The hydrochloride was prepared by dissolving $1 \mathrm{~g}$ of XI in $15 \mathrm{ml}$ of ether and bubbling hydrogen chloride through the solution for $5 \mathrm{~min}$. The white solid, obtained on recrystallization from hot ethanol containing a drop of concentrated $\mathrm{HCl}$, melted with decomposition at 178 to $179^{\circ} \mathrm{C}$.

Anal: Calcd. for $\mathrm{C}_{10} \mathrm{H}_{14} \mathrm{ClNO}$ : C, $60.2 ; \mathrm{H}, 7.1$; N, 7.0. Found: C, 59.9; H, 7.4; N, 6.9.

3-Allyl-2-methoxyphenol (3-Allylguaiacol) (III). 3-Allyl-2-methoxyaniline was diazotized, and the resulting diazonium salt converted to the phenol. Reverse diazotization appeared to give slightly better yields than the usual addition of sulfuric acid followed by nitrite. Yields improved when only small quantities of diazonium salt were decomposed; however, they varied considerably from one preparation to another.

3-Allyl-2-methoxyaniline (5 g, 0.03 mole) was suspended in $25 \mathrm{ml}$ of water, and solutions of $1.15 \mathrm{~g}$ of $\mathrm{NaOH}$ in $6.5 \mathrm{ml}$ of water and of $4 \mathrm{~g}$ of $\mathrm{NaNO}_{2}$ in 15 $\mathrm{ml}$ of water were added successively. The entire solution, cooled to $0{ }^{\circ} \mathrm{C}$, was then quickly added, with stirring, to $4.5 \mathrm{~g}$ of concentrated $\mathrm{H}_{2} \mathrm{SO}_{4}$ (previously cooled to $0{ }^{\circ} \mathrm{C}$ ) and kept in an ice bath. The excess nitrite was decomposed by the addition of urea until a negative test for nitrite was obtained with starchiodide paper. The resulting cold solution was stored in a refrigerator until needed.

A solution prepared from $150 \mathrm{~g}$ of anhydrous $\mathrm{Na}_{2} \mathrm{SO}_{4}, 108 \mathrm{ml}$ of concentrated $\mathrm{H}_{2} \mathrm{SO}_{4}$ and $100 \mathrm{ml}$ of water, in a three-necked flask equipped for steam distillation, was kept at 135 to $150{ }^{\circ} \mathrm{C}$ by a surrounding oil bath. The cold solution of the diazonium salt was slowly added from a separatory funnel while steam was passed through the flask; the volatile products were thus steam-distilled immediately after decomposition of the diazonium salt. ${ }^{6}$ The distillate was extracted with ether, the ether extracts were washed with 10-percent, aqueous $\mathrm{NaHCO}_{3}$, and the phenol was extracted from the ether layer with 10percent aqueous $\mathrm{NaOH}$. After ether extraction of the acidified solution and evaporation of the solvent 0.85 to $2.2 \mathrm{~g}$ ( 17 to $44 \%$ ) of 3 -allyl-2-methoxyphenol was obtained; bp 92 to $93{ }^{\circ} \mathrm{C} / 4 \mathrm{~mm}, n_{\mathrm{D}}^{26}=1.535$.

Anal: Calcd. for $\mathrm{C}_{10} \mathrm{H}_{12} \mathrm{O}_{2}: \mathrm{C}, 73.1 ; \mathrm{H}, 7.4$. Found: C, 72.9; H, 7.3.

The infrared spectrum (fig. 2) shows absorption bands in the regions in which the $-\mathrm{CH}=\mathrm{CH}_{2}$ group absorbs, namely, 5.39 to $5.55 \mu ; 7.04$ to $7.09 \mu ; 7.69$ to $7.76 \mu ; 10.05$ to $10.15 \mu$; and 10.93 to $11.05 \mu$. [11]. The areas in which the trans $-\mathrm{CH}=\mathrm{CH}-$ group absorbs $(7.67$ to $7.72 \mu$ and 10.31 to $10.42 \mu$ ) fall on the sides of two of these bands, and hence it is not possible to state with certainty that there is

${ }^{6}$ Because of tar formation, the solution of the diazonium salts was introduced, in later reactions, through a cold-finger addition tube (as suggested by Lambooy [10]); the tube reached to within $1 \mathrm{~cm}$ of the surface of the hydroysis mixture. no absorption due to trans $-\mathrm{CH}=\mathrm{CH}-$ groups. Absence of an absorption band near $14.49 \mu$ indicates that there is very little, if any, cis $-\mathrm{CH}=\mathrm{CH}-$ present. Before the final fractionation the phenol contained a considerable amount of ethanol. The mechanism of the formation of this product is not known.

To establish the identity of III it was converted to 2,3-dimethoxybenzoic acid (o-veratric acid) (XIV) via 1-allyl-2,3-dimethoxybenzene (XIII). 3-Allyl-2methoxyphenol (1.5 g, 0.09 mole) dissolved in $16 \mathrm{ml}$ of 15-percent $\mathrm{NaOH}$ was cooled, and $2.0 \mathrm{ml}$ of dimethyl sulfate was rapidly added to the stirred solution. After $15 \mathrm{~min} 2 \mathrm{ml}$ of dimethyl sulfate was added, and the solution was refluxed for $2 \mathrm{hr}$; $5.5 \mathrm{ml}$ of 10 -percent $\mathrm{NaOH}$ was then added, the solution refluxed for 2 more hr, cooled, and extracted with ether. The ether extract was dried and evaporated, and the residue distilled at 65 to $68{ }^{\circ} \mathrm{C} / 2.5$ $\mathrm{mm}$. Yield: $1.0 \mathrm{~g}$ (60 percent), $n_{\mathrm{D}}^{25}=1.524$. The same physical constants were obtained for XIII, synthesized from o-eugenol according to the procedure of Mauther [12].

For the conversion of XIII to XIV, $1 \mathrm{~g}$ of 1 -allyl2,3-dimethoxybenzene was refluxed for $1 \frac{1 / 2}{\mathrm{hr}}$ with $3.6 \mathrm{~g}$ of powdered potassium permanganate dissolved in $40 \mathrm{ml}$ of water. The mixture was filtered through a fritted glass funnel, and the filtrate was evaporated to about $20 \mathrm{ml}$, cooled, and acidified with dilute $\mathrm{H}_{2} \mathrm{SO}_{4}$. The resulting precipitate, after successive recrystallizations from benzene and water, melted at 123 to $123.5^{\circ} \mathrm{C}$. The melting point was unchanged by mixture with authentic 2,3-dimethoxybenzoic acid.

Conversion of III to 2-Methoxy-3-propenylphenol. 3-Allyl-2-methoxyphenol (III) was refluxed with alcoholic KOH for $16 \mathrm{hr}$ by a method analogous to the preparation of isochavibetol [2]; bp $109^{\circ} \mathrm{C} / 7 \mathrm{~mm}$, $n_{\mathrm{D}}^{25}=1.556$. As indicated by the infrared spectrum the product was an impure mixture of $c i s$ and trans 2-methoxy-3-propenylphenol.

\subsection{Chavibetol (5-Allylguaiacol) (IV)}

Eugenol methyl ether (1-allyl-3,4-dimethoxybenzene) was synthesized in 88-percent yield according to the procedure of Luff, Perkin, and Robinson [13]. Demethylation of this compound with Grignard reagent, conducted as suggested by Schöpf and coworkers [3] gave a mixture of eugenol and chavibetol.

It was found that these impure eugenol-chavibetol mixtures could be separated by gas chromatography with a diisodecyl phthalate column heated to $175^{\circ} \mathrm{C}$ and a hydrogen flame detector. Larger quantities of the isomers were most conveniently separated by a chromatograph designed for synthetic work; this employed Apiezon $\mathrm{J}$ on a $\mathrm{C}-22$ firebrick column, with a column temperature of $180{ }^{\circ} \mathrm{C}$ and a pressure of $10 \mathrm{lb} / \mathrm{in}^{2}$. The infrared spectrum of chavibetol is shown in figure 2 .

The chavibetol was characterized by conversion to isochavibetol ( $\mathrm{mp} 95$ to $96{ }^{\circ} \mathrm{C}$ ) as described by Hirao [2]. 


\subsection{Preparation of Intermediates in Attempted Synthesis of Chavibetol}

Prior to the gas chromatographic separation described in section 2.3, the preparation of chavibetol from VIII (fig. 1) was attempted. Although the preparation was not completed for lack of material, two new intermediates (X and XII) were obtained. The following sections describe their preparation.

5 - Allyl - 2 - methoxyacetanilide (5 - Allyl - o - acet anisidide) $(X)$. 2-Acetamido-4-allylphenol (5 g, 0.026 mole) was dissolved in $25 \mathrm{ml}$ of 5.5 -percent aqueous $\mathrm{NaOH}$ (0.034 mole). During a 15 -min period, $3.8 \mathrm{ml}$ (0.04 mole) of dimethyl sulfate was added, while the solution was stirred in an atmosphere of nitrogen. During $90 \mathrm{~min}, 3 \mathrm{ml}$ of dimethyl sulfate was added, together with sufficient $\mathrm{NaOH}$ solution to keep the mixture alkaline. The mixture was then heated at $40{ }^{\circ} \mathrm{C}$ for $45 \mathrm{~min}$, and extracted with ether. After drying and evaporation of the solvent, the residue was recrystallized from ligroin to vield long, colorless needles, mp 56.5 to $57^{\circ} \mathrm{C}$; yield; $4.50 \mathrm{~g}$ (84 percent).

Anal: Calcd. for $\mathrm{C}_{12} \mathrm{H}_{16} \mathrm{NO}_{2}: \mathrm{C}, 70.3 ; \mathrm{H}, 7.4 ; \mathrm{N}$, 6.8. Found: C, 70.3; H, 7.6; N, 6.5. The infrared spectrum is given in figure $3 \mathrm{~d}$.

5-Allyl-2-methoxyaniline Hydrochloride (5'-Allylo-anisidine Hydrochloride) (XII). 5-Allyl-2-methoxyacetanilide (3.8 g, 0.019 mole) dissolved in $10 \mathrm{ml}$ of $6 \mathrm{~N} \mathrm{HCl}$ was refluxed for $45 \mathrm{~min}$, and the solution was concentrated by evaporation under reduced pressure. The resulting precipitate on recrystallization from an aqueous solution acidified with a little $\mathrm{HCl}$ gave colorless needles (mp 170 to $172^{\circ} \mathrm{C}$ ); yield (including recovery from mother liquor); $3.15 \mathrm{~g}$ (85 percent).

Anal: Calcd. for $\mathrm{C}_{10} \mathrm{H}_{14} \mathrm{ClNO}: \mathrm{C}, 60.2 ; \mathrm{H}, 7.1 ; \mathrm{N}$, 7.0. Found: C, $60.2 ; \mathrm{H}, 7.2 ; \mathrm{N}, 6.8$.

A solution of the hydrochloride $(3 \mathrm{~g}$ in $15 \mathrm{ml}$ of water) was made slightly alkaline with 2-percent $\mathrm{NaOH}$ and extracted with ether. After evaporation of the solvent a liquid remained which sublimed during attempted vacuum distillation. The crystalline product, on successive recrystallization from 70-percent aqueous ethanol and ligroin, gave colorless scales, $\mathrm{mp} 47^{\circ} \mathrm{C}$. The presence of an absorption band at $10.32 \mu$ suggests that some isomerization to the trans propenyl group had taken place. Elementary analysis indicated that the compound was impure.

\subsection{Synthesis of Allyl 2-Benzoyloxyphenyl Ether and Its Behavior in a Claisen Rearrangement}

In one of the alternative procedures for the synthesis of 3-allyl-2-methoxyphenol, allyl 2-benzoyloxyphenyl ether was synthesized and its Claisen rearrangement investigated.

Allyl 2-Benzoyloxyphenyl Ether (XV). Catechol monobenzoate was prepared in 55-percent yield by benzoylation of catechol at $6{ }^{\circ} \mathrm{C}$ according to the procedure of Donadio [14]. A solution prepared from eatechol monobenzoate (168 g, 0.78 mole), anhydrous $\mathrm{K}_{2} \mathrm{CO}_{3}(110 \mathrm{~g}, 0.80$ mole), allyl bromide
(103 g, 0.85 mole) and $750 \mathrm{ml}$ of dry acetone was refluxed overnight with stirring. The product was extracted with ether, and the extract washed successively with 5-percent $\mathrm{NaOH}$ and water. After evaporation of the solvent the compound was recrystallized from an ether-petroleum ether mixture; yield; $121 \mathrm{~g}(61 \%) ; \mathrm{mp} 44^{\circ} \mathrm{C}$.

Anal: Calcd. for $\mathrm{C}_{16} \mathrm{H}_{14} \mathrm{O}_{3}: \mathrm{C}, 75.6 ; \mathrm{H}, \quad 5.6$. Found: $\mathrm{C}, 75.6 ; \mathrm{H}, 5.7$.

Behavior of Allyl 2-Benzoyloxyphenyl Ether on Claisen Rearrangement. Attempts were made to obtain 2-allyl-6-benzoyloxyphenol by Claisen rearrangement of allyl 2-benzoyloxyphenyl ether. The allyl ether $(10 \mathrm{~g}, 0.04$ mole) was refluxed at 180 to $200^{\circ} \mathrm{C}$ in a nitrogen atmosphere for $30 \mathrm{~min}$.

Separation of the reaction products yielded considerable quantities of starting materials, benzoic acid, and a phenol which distilled at 107 to 115 ${ }^{\circ} \mathrm{C} / 7 \mathrm{~mm}$. The distillate $\left(n_{\mathrm{D}}^{26}=1.5588\right)$ crvstallized on storage in a refrigerator; yield: $2.2 \mathrm{~g}(37 \%)$.

The phenol was identified as impure 1-allyl2,3-dihydroxybenzene by (1) its infrared spectrum, which showed the presence of allyl and phenol groups and the absence of ester linkages, (2) a positive test for a catechol derivative [15], and (3) methylation with dimethyl sulfate and subsequent permanganate oxidation to 2,3-dimethoxybenzoic acid.

The authors thank Miss M. Kathryn Wharton, Applied Polymer Standards and Research Section for the infrared analyses, E. Deardorff of the Standards Reference Materials Section for the elementary analyses, R. J. Vanapeldoorn, Walter Reed Army Institute of Research for assistance in the gas chromatographic separation, and Dr. Harriet Frush for many valuable suggestions.

\section{References}

[1] H. I. Copeland, G. M. Brauer, W. T. Sweeney, and A. F. Forziati, J. Research NBS 55, 133 (1955) RP2611.

[2] N. Hirao, Bull. Chem. Soc. Japan 11, 179 (1936).

[3] C. Schöpf, E. Brass, E. Jacobi, E. Jorde, W. Mocnik, L. Neuroth, and W, Salzer, Ann. 544, 30 (1940).

[4] M. Pal'gi, J. Gen. Chem. U.S.S.R. 28, 2275 (1958).

[5] C. F. H. Allen and J. W. Gates, Org. Syntheses, Collective Vol. III, p. 418.

[6] H. E. Fierz-David and W. Kuster, Helv. Chim. Acta 22, 82 (1939).

[7] B. D. Tiffany, J. Am. Chem. Soc. 70, 592 (1948).

[8] Z. Budesinsky and E. Rockova, Chem. Listy 48, 427 (1954).

[9] D. C. Shrewsberry, Spectrochim. Acta 16, 1294 (1960).

[10] J. P. Lambooy, J. Am. Chem. Soc. 7\%, 5327 (1950).

[11] L. J. Bellamy, Infra-red Spectra of Complex Molecules, 2 d ed. (John Wiley \& Sons, New York N.Y., 1958).

[12] F. Mauther, J. Pract. Chem. 148, 95 (1937)

[13] B. D. W. Luff, W. H. Perkin, Jr., and R. Robinson, J. Chem. Soc. 9\%, 1138 (1910).

[14] R. E. Donadio, Master's thesis, University of Detroit, Detroit, Mich., June 1952, p. 13-14.

[15] F. Feigl, Spot Tests in Organic Analysis, 6th ed., p. 416 (Elsevier Publishing Co., New York, 1960).

(Paper 67A3-213) 